\title{
Editorial
}

\section{Erythema Scarlatiniforme Desquamativum Recidivans - A Forgotten Disease (Recurring Localized Scarlatiniform Scaled Erythema)}

\author{
H. Beltraminelli ${ }^{a}$ P. Itin ${ }^{b}$ \\ ${ }^{a}$ Dermatologische Klinik, Universitätsspital Basel, Basel, und ${ }^{b}$ Abteilung für Dermatologie, Kantonsspital Aarau, \\ Aarau, Schweiz
}

Erythema scarlatiniforme desquamativum recidivans (ESDR; synonyms: morbus Féréol-Besnier, dermatitis exfoliativa acuta benigna) is a rare (or almost forgotten) disease first described by Féréol in 1876 [1]. Thereafter about more than 60 articles appeared mainly in the French and German literature (most during the 50s and 60s); after a long period of silence about this topic, in 1985 a group from Munich's University [2] finally published an article which describes 2 cases of ESDR. In this issue of Dermatology, Braun-Falco et al. [3] report a further case of recurring localized scarlatiniform scaled erythema type Féréol-Besnier.

During the last 6 years, we encountered 7 patients with localized and 1 with generalized ESDR (table 1). We think that this entity is not as rare as taught some years ago. To increase the attention to this disease we summarize our experiences with ESDR.

ESDR is characterized by recurrent episodes of fever accompanied by a macular erythematous exanthema beginning on the trunk with rapid secondary generalization; lastly the head, hands and feet are affected, too. The skin eruption does not itch or burn, there are no blisters, no papules or pustules and no hyperkeratosis. Eczematous lesions are absent; in fact, at the beginning it is a macular confluent erythema without other further primary lesions. The mucosae and conjunctivae are usually not affected. Before the rash disappears, a typical desquama- tion starts (within 1 week after the beginning) with an extensive gross lamellar peeling of the trunk, pityriasiform scaling of the head and highly characteristic desquamation of the hands and feet.

ESDR exists in a generalized and localized variant, the latter mainly involving the hands and feet [3].

The exanthema is usually preceded by a prodromal phase with general malaise, nausea, headache, muscle pain, gastrointestinal disorders, sometimes bronchitis and joint pain. Other associated symptoms are Beau lines of the nails, conjunctivitis, pharyngeal inflammation, white-gray tongue, epistaxis, hair loss [4], infections (pneumonia, enteritis, Aspergillus niger skin infection), lymph node swelling and glomerulonephritis.

In the localized variant, the leading symptom is the suggestive asymptomatic gross lamellar peeling of the hands and feet; the prodromi and the associated symptoms (even the erythematous rash) are clearly milder or may even be absent. In general one needs a high index of suspicion to think about ESDR in these cases.

Interestingly, in the general variant, despite the fact that the rash covers most parts of the skin, the patients do not feel very ill.

The first bout of the disease lasts about 2-4 weeks; later relapses are shorter and milder. They can occur after days, weeks, months or even years after the first episode.

\section{KARGER \\ Fax +4161306 1234 E-Mail karger@karger.ch} www.karger.com 
Table 1. Patient data

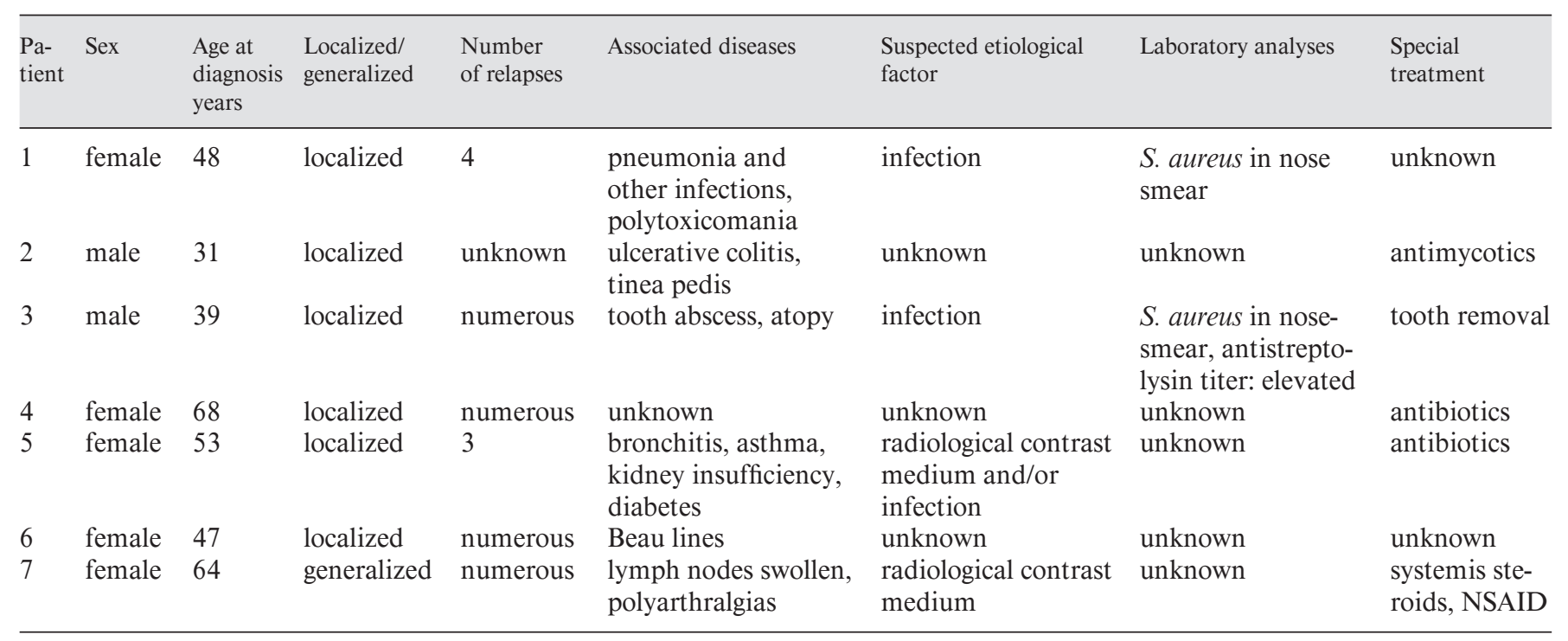

NSAID = Nonsteroidal anti-inflammatory drugs.

Biological analyses show an elevation of the white blood cells, eosinophils, of the C-reactive protein and the sedimentation rate; sometimes, one can observe transient proteinuria, microhematuria [5] and elevation of the antistreptolysin titer.

Histology is unspecific, showing orthohyperkeratosis, parakeratosis, discrete acanthosis and only minimal inflammation of the superficial dermis; in the literature, other signs are discussed, such as a capillaritis and a divided stratum corneum with a thick orthokeratosis above a parakeratotic layer.

The pathogenesis of ESDR is not clear, in most of the published cases an external factor such as a viral or bacterial infection (staphylococci or streptococci) or adverse drug effects in association with individual susceptibility (hyperergic reaction) are speculated as triggers of ESDR.

Many associations with a less scientifically demonstrable correlation are suggested: aseptic meningitis [6], atopy, adverse drug reactions (antibiotics, vitamins [7] and antidiabetic drugs), liver disease [8], eosinophilic pneumonia [9], infectious enteritis and lymphoma.

In many cases of ESDR, bacterial infection with Staphylococcus or Streptococcus could be detected in a smear; one presumes - as it happens in the staphylococcal scalded skin syndrome - the produced toxins to be responsible for the superficially gross lamellar desquamation of the skin. Such a desquamation could be a consequence of a viral infection too, but some cases in the literature where serological and smear analyzes were done could not confirm this hypothesis.

Six of our patients had the localized variant of ESDR; most of them had a relapsing course of peeling hands and feet for several years.

We observed correlations with infections (pneumonia, tooth abscess, bronchitis), to inflammatory diseases (ulcerative colitis), to atopy and medications (radiological contrast medium). One patient had a high antistreptolysin titer and Staphylococcus aureus in the nose smear.

Two patients showed a rapid improvement of the disease after a short antibiotic treatment.

The one with the generalized disease had mediastinal swollen lymph nodes and high inflammatory parameters at laboratory analyses; infections and lymphoma had been ruled out many times during the course of the disease.

There are many important differential diagnoses to be ruled out: eczema - some patients have an atopic diathesis and some have eczemas, but the history and the histology are not characteristic of eczema; toxic epidermal necrolysis - most of the patients with ESDR do not take any medication and the clinical picture of ESDR is less dramatic; scarlet fever - the absence of a raspberry tongue and of a clinically relevant streptococcal infection points against this diagnosis; in cases with staphylococcal scalded skin syndrome, relapses are unusual; psoriasis vulgaris 


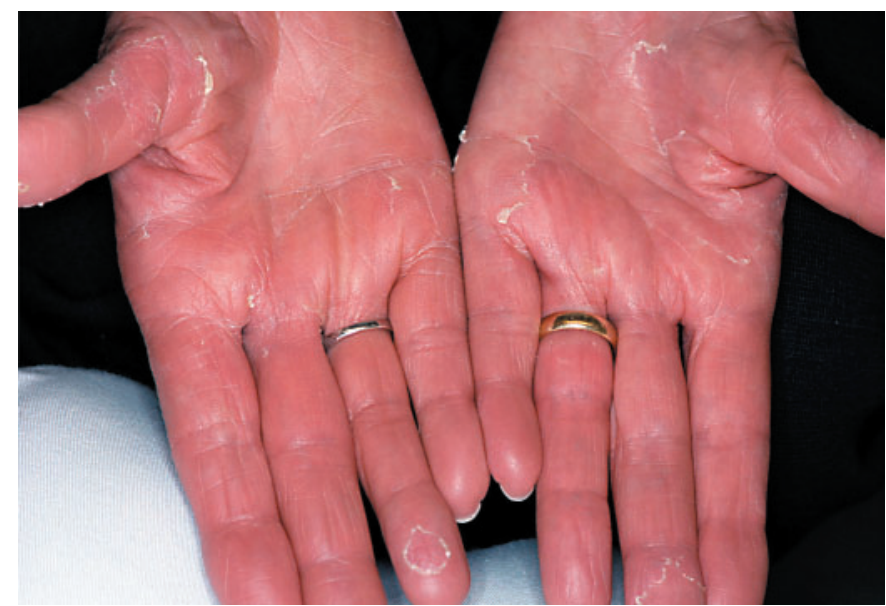

Fig. 1. Gross lamellar peeling of the palms without blisters or pustules.

is more chronic, a complete healing of the lesions after desquamation is uncommon; pityriasis rubra pilaris shares the characteristic peeling of the hands and feet with ESDR but has a more chronic nature; pellagra is a possible differential diagnosis in case of malnutrition/malabsorption; Kawasaki syndrome - swollen lymph nodes and raspberry tongue are absent in ESDR; peeling skin syndrome [10] could be congenital or manifests itself in early childhood (most ESDR patients are adults), the clinical picture is a noninflammatory exfoliation; erythrokeratolysis hiemalis [11] begins normally in early childhood and relapses are typical in winter; necrolytic acral erythema is

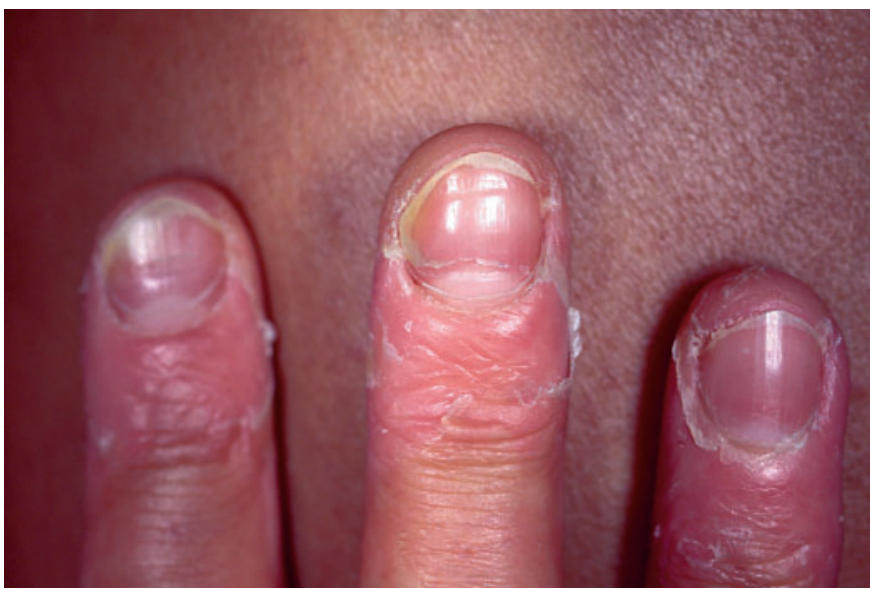

Fig. 2. Gross lamellar peeling of the fingers and Beau lines of the nails.

associated with hepatitis C or zinc deficiency; palmoplantar keratoses - actually ESDR is an exfoliation and a peeling of the skin more than a hyperkeratosis; mercury intoxication - an occupation and hobby history permits to rule out this diagnosis; desquamatio aestivalis.

ESDR is self-limited and disappears spontaneously within 2-3 weeks; there is no standardized treatment, steroids could not influence the course of the disease, even in the acute phase, or as a relapse-prophylaxis, in some cases systemic antibiotic treatment had a positive effect on the disease; the best treatment is symptomatic.

\section{References}

1 Lausecker H: Das Erythema scarlatiniforme desquamativum recidivans. Arch Dermatol Syphil 1954;198:529-548.

2 Landthaler M, Michalopoulos M, Schwab U, Dorn M: Erythema scarlatiniforme desquamativum recidivans localisatum. Hautarzt 1985; 36:581-585.

3 Braun-Falco M, Kasche A, Worret WI: Recurring localized scarlatiniform scaled erythema Féréol-Besnier. Dermatology 2006;212:253257.

4 Rosellen E: Erythema scarlatiniforme desquamativum recidivans. Med Welt 1966;48: 2648-2649.
5 Thiers H, Fayolle J, Coeur P, Laurent J: Érythème scarlatiniforme récidivant avec hématurie microscopique contemporaine chez une tuberculeuse pulmonaire diabétique traitée par le Glucidoral: responsabilité étiologique du Glucidoral. Bull Soc Fr Dermatol Syphiligr 1964;71:601-603.

6 Meyer-Lindenberg A, Holz M: Féréol-Besnier disease with associated recurrent meningitis. J Neurol Neurosurg Psychiatry 1997;62:297.

7 Bieber T: Érythème scarlatiniforme généralisé, éruption toxique par hautes doses de vitamines $\mathrm{B}_{1}$. Bull Soc Fr Dermatol 1957;64:747-748.

8 Miedzinski F, Pawlowski S: Beitrag zur Kenntnis des Erythema scarlatiniforme recidivans. Dermatologica 1955;112:36-43.
9 Riegel K, Korting GW: Zur Kenntnis viscerocutaner Wechselwirkungen mit hoher Bluteosinophilie unter dem Bilde des Löfflerschen Lungeninfiltrates und des Erythema scarlatiniforme desquamativum recidivans. Arch Exp Dermatol 1957;205:235-244.

10 Brusasco A, Veraldi S, Tadini G, Caputo R: Localized peeling skin syndrome: case report with ultrastructural study. Br J Dermatol 1998; 139:492-495.

11 Danielsen AG, Weismann K, Thomsen HK: Erythrokeratolysis hiemalis (keratolytic winter erythema): a case report from Denmark. J Eur Acad Dermatol Venereol 2001;15:255-256. 